\title{
A Time of Reflection and Renewal
}

\author{
Susan VanDeVelde-Coke, RN, MA, MBA, PhD \\ Executive Vice-President, Chief Health Professions \& Nursing Executive \\ Sunnybrook Health Sciences Centre \\ President, ACEN \\ Joy Richards, RN, PhD \\ Vice-President Collaborative Practice, People Services \\ and Chief Nursing Executive \\ The Scarborough Hospital \\ Past President, ACEN
}

Last year was a particularly difficult year for the healthcare industry. The steady downward trajectory of the economy in 2009, the restructuring of provincial healthcare governance structures, the H1N1 pandemic and the pressure on chief nursing executives to consider alternative skill mixes and role changes have had an impact on every acute, rehab, mental health, long-term and community healthcare organization across the country. Key nursing leadership positions at many levels of our organizations disappeared, as regionalization and cutbacks took their toll - travel budgets, conference funds and approval for membership in organizations such as ACEN have been severely curtailed. These restrictions have had an impact on ACEN members' ability to come together face to face on a regular basis to discuss emerging trends in the provinces, and to share mechanisms for coping with the restructuring efforts in the jurisdictions. As 2009 progressed, it became apparent that ACEN will need to depend on teleconferencing, webcasting and other technologies to replace the face-to-face meetings of the past.

The purpose of this issue's column is to share the results of the February 4-5 ACEN Annual General Meeting (AGM) and to present the directions for 2010/11. Our membership has established ACEN's strategic directions and the following goals for the coming year:

1.Supporting and influencing the health of Canadians: Through its strategic coalitions and partnerships, ACEN influences and participates in setting directions 
for nursing, health policy and healthcare delivery in Canada that improve the health of Canadians.

2. Contributing to the advancement of nursing: ACEN leads a community of practice to share, discuss and debate strategies and innovations that advance nursing clinical practice, education, research and management.

3. Supporting the executive nursing leadership in Canada: ACEN supports the development of current and emerging executive nurse leaders across Canada.

Over this past year, ACEN addressed these goals in variety of ways.

- Strategic direction \#1: ACEN was represented at a recent national forum to review the mandate of the academic health centres in Canada. The forum was also attended by representatives from provincial governments, universities, national organizations and healthcare professional groups. The keynote speaker presented the changes to academic health structures taking place in Britain and Europe, a possible precursor of suggested change in Canada, for example, as being discussed in Alberta.

ACEN is also participating in the Quality Workplace, Quality Health Care (QWQHC) forum and discussions. Many of ACEN's member organizations have signed the QWQHC charter, which mandates the organization to implement the initiatives necessary to support high-quality workplaces for nursing staff. Many of the QWQHC principles and components required for a healthy workplace are now part of the Accreditation Canada QMENTUM criteria.

- Strategic direction \#2: ACEN conducted a "Cross-Country Check-Up Teleconference" in December 2009. Representatives from British Columbia, Alberta, Ontario and Nova Scotia provided updates on key issues affecting their regions, followed by a question period and open discussion. Common themes that emerged during this session, and that were elaborated upon during the AGM, included health system re-organization, changes to models of care and skill mix, changes to senior nursing positions and use of evidence-based practice to implement innovation.

ACEN is represented on the planning committee of the Biannual Nursing Leadership conference, which took place in 2009. Planning has just started for the 2011 conference.

ACEN is the sponsor of the Canadian Journal of Nursing Leadership (CJNL), published by Longwoods. An editorial committee, including ACEN members, is responsible for selecting, through a peer-reviewed process, the papers in the journal, which is published four times per year. CJNL has the largest readership of all of the Longwoods publications. This is a significant accomplishment for ACEN members to be proud of, especially as the journal was begun by a small group of ACEN members without support from a publisher or editors. 
- Strategic direction \#3: The ACEN Executive Committee has identified a need to enhance awareness of ACEN as an organization among non-members and to clarify the expectations of membership among both existing and potential members. In March 2009, with the support of funds from the Health Canada Office of Nursing Policy, a consultant group was contracted to review the findings from the 2007 ACEN survey and to interview current, non-renewing and potential ACEN members with regard to these issues. The findings from this survey have been utilized to support a concerted effort to retain current members, encourage past members to rejoin and attract new members among executive nurses and senior nurse leaders in education, research and policy making. The full findings of this review were published in the fall issue of CJNL (Volume 23, Number 1).

However, over this past year, we noted that many organizations have imposed restrictions on corporate memberships, affecting the sustainability of our membership, and thus our budget. To address this issue, the ACEN executive put forward a proposal at the AGM to change the bylaws to delete the organizational memberships and replace them with individual memberships. This motion was approved at the February 2010 AGM.

\section{Strategic Directions for 2010/11}

A number of major decisions were made at the February AGM that will have an impact on the three strategic directions of the organization.

- Strategic direction \#1: Supporting and influencing the health of Canadians. The following direction has been given to the ACEN policy committee:

One or two key policies or action papers will be authored in the coming year that address major issues facing ACEN members. Examples of these issues include skill-mix changes, the use of alternative roles in the delivery of healthcare and new models of care delivery. We are seeking input from our members on the policy issues that are of most interest and usefulness to them.

ACEN will continue our participation in the national group discussing new strategic directions for academic health sciences centres, including new methods of governance. In addition, ACEN will collaborate with the Canadian Nurses Association (CNA) and other national nursing organizations on pertinent policy issues.

- Strategic direction \#2: Contributing to the advancement of nursing. A second cross-country check-up was held at the AGM. Many of the same themes emerged from across the country, including the impact of regional restruc- 
turing, budget constraints on nursing roles and skill mix. The membership supported the notion that regular sharing of current government policies and their effect on healthcare provision is a deliverable for ACEN. As a result:

Regular cross-country check-up teleconferences will be held for the ACEN membership throughout 2010/11.

- Strategic direction \#3: Supporting the executive nursing leadership in Canada. The ACEN bylaws were changed at the AGM to delete the organizational membership and replace it with a new category of individual membership. The individual membership was fixed at $\$ 400$. The category of individual membership includes the chief executive nurse and the next level of nursing management in the organization. Organizations that are welcome to join ACEN include academic teaching and community hospitals, complex continuing care, rehabilitation, mental health, long-term care, public health and community agencies.

ACEN has also committed to using technology to bring its membership together in new and innovative ways. We now have a Facebook group to support social networking. At the AGM we used Web-based technology to bring our Pan-Canadian membership together, an approach that worked very well. Finally, ACEN is exploring new and innovative partnerships with organizations and associations (for example, the CNA, Longwoods) that can provide synergistic energy to spark creativity and leverage each other's strengths. The ACEN executive envisions that this collaboration will allow our membership to share innovations and evidence-based practice.

In summary, the AGM resulted in new goals to deliver on our strategic directions. The ACEN executive commits to achieving these goals. However, the executive needs the current and future members of ACEN to assist in achieving them. You can help by getting involved in ACEN, soliciting new members or joining a committee, and volunteering to represent your province in the cross-country check-ups.

This is going to be a seminal year in the healthcare system. It is important that nursing leaders across the country share their ideas, solutions and evidence. You are not alone. Join ACEN. Be part of the team that is seeking viable solutions to our current issues. We are here for you, just a phone call or Facebook entry away. To learn more about ACEN, you may go to our website: www.acen.ca. If you are interested in participating, please contact Nan Brooks at nbrooks@consultingcadre.net or 647-200-1682. 